American Journal of Applied Sciences 7 (11): 1500-1503, 2010

ISSN 1546-9239

(C) 2010 Science Publications

\title{
A Numerical Treatment of Air Flow Model in the Area Under the Station Platform of Thailand BTS Sky Train
}

\author{
Nopparat Pochai \\ Department of Mathematics, Faculty of Science, \\ King Mongkut's Institute of Technology Ladkrabang, Bangkok 10520
}

\begin{abstract}
Problem statement: The area under Phayathai station platform of sky train in Bangkok, Thailand, has a problem of air pollution control. Approach:The Bangkok Mass Transit System Company tries to set up the electric fans inside the area for air flow improvement. Results: The flow of the air is still not smooth and the air quality is still lower than standard. The assumption of the research that is the flow obstructs by the platform structures. Conclusion: In this research, a mathematical model can be simulating the causes of the flow obstacle. The numerical solution of the model is obtained by using a finite element technique.
\end{abstract}

Key words: Air flow model, flow velocity, numerical treatment, velocity potential, mathematical model, Bangkok sky train, finite element, governing equation

\section{INTRODUCTION}

The mathematical models of the small particles transport by wind are considered to many geophysical (El-Baz et al., 1990) and environmental problems (Sharan et al., 1996). The dynamics of each transport are governed by the wind speed, the sizes of particles and the turbulent eddies that disperse and diffuse the particles. The case includes smoke from industrial chimneys and small snow flakes (Smith, 1957) and (Takeuchi, 1980) to fine soil particles. The wind speed has a logarithmic profile (Pasquill, 1962), and then the turbulence of the air flow is an important factor of the model accuracy (Townsend, 1976). For the moderate wind speeds, (Gillette and Goodwin, 1974) studied the simplest possible form of diffusion equation which arise frequently in the air pollution problem area. Hassan and Eltayeb (1991; 1992), extended to concern the variation of concentration to find that the distribution of the concentration is very much dependent on the distance of the wind direction. Hassan and Eltayeb (1993), they extend their study to the saturation in which the source is at the ground level. The effect of air pollution on ozone layer thickness on troposphere over the state of Kuwait (Al Jeran and Khan, 2009), and the effect of size of heated obstruction within room on three dimensional air flow has been characterized (Ahmed et al., 2010). Pochai (2009), gives the mathematical model to investigate the air flow in the area under the BTS station platform. The governing equation with the boundary condition is given. In this research, the finite element method is used to solve the model.

\section{MATERIALS AND METHODS}

The mathematical model:

The governing equation: The two-dimensional flow of the air in the domain $\Omega$ in the rectangular ordinate $(\mathrm{x}, \mathrm{y})$ is considered. If the flow is irrotational, then the velocity components $\mathrm{u}$ and $\mathrm{v}$ are express in terms of velocity potential $\Phi$ as follows (Ninomiya and Onishi, 1991):

$\mathrm{u}=\frac{\partial \Phi}{\partial \mathrm{x}}, \mathrm{v}=\frac{\partial \Phi}{\partial \mathrm{y}}$

In this problem, the affect of compression will be neglected. Then the equation of continuity becomes:

$\frac{\partial \mathrm{u}}{\partial \mathrm{x}}+\frac{\partial \mathrm{v}}{\partial \mathrm{y}}=0$

Substitution Eq. 1 into Eq. 2, we get the equation:

$\frac{\partial^{2} \Phi}{\partial \mathrm{x}^{2}}+\frac{\partial^{2} \Phi}{\partial \mathrm{y}^{2}}=0$

The domain boundary $\Gamma=\partial \Omega$ can be classified into two types: $S_{1}$ the velocity potential $\Phi_{\mathrm{B}}$ is specified and $\mathrm{S}_{2}$ the normal component of the velocity $\mathrm{V}_{\mathrm{n}}$ is specified and total boundary $\Omega$ is $\Omega=\mathrm{S}_{1} \cup \mathrm{S}_{2}$. The boundary condition on $S_{1}$ and $S_{2}$ are:

$\Phi=\Phi_{\text {B }} \quad$ on $S_{1}$ 
Am. J. Applied Sci., 7 (11): 1500-1503, 2010

$\frac{\partial \Phi}{\partial \mathrm{n}}=\mathrm{V}_{\mathrm{n}}$ on $\mathrm{S}_{2}$

Boundary condition: By the Fig. 1, it is obtained that the flow in two-dimensional $\mathrm{X}, \mathrm{Y}$ planes is uniform speed in X-direction. A column with the circular cross section of radius $1.5 \mathrm{~m}$ is placed perpendicularly to the flow field. Since the air flow is assumed to be inviscid and irrotational, it is obtained that the flow around the column is expressible as a potential flow.

By the symmetry of the problem, an upper half of the full geometry will be considered. The part of the left boundary $\mathrm{AB}$ represents the inlet, the air flow velocity $\mathrm{u}=1 \mathrm{~m} \mathrm{sec}^{-1}, \mathrm{v}=0 \mathrm{~m} \mathrm{sec}^{-1}$. On boundary BC and DE are lines of symmetry. The semicircle $\mathrm{CD}$ is assumed to be a slipping boundary. Then the normal component of the air flow velocity will be zero. The left boundary EF is the outlet of the flow that the air is assumed to flow out at the uniform velocity. Then the tangential component of flow velocity will be zero. The top boundary AF is a far field boundary, which is non affective from the column. Then the boundary AF forms a streamline.

The revision of the boundary condition for the area under the station platform of Bangkok sky train: The revised the boundary conditions in terms of the velocity potential $\Phi$ as follows, $\Phi=0$ along the inlet $\mathrm{AB}$, the velocity to $\mathrm{BCDE}$ and $\mathrm{AF}$ are equal to zero, $\mathrm{V}_{\mathrm{n}}$ $=0$ in Eq. 4 . Since the distance between the front and the end of the platform is $30 \mathrm{~m}$. and using Eq. 6 of (Pochai, 2009), it is obtained that the air flow outlet velocity $\Phi$ along boundary $\mathrm{EF}$ is:

$$
\Phi=\int_{0}^{30} \mathrm{udx}=30 \mathrm{~m}^{2} \mathrm{sec}^{-1}
$$

It is obtained the summarize of the boundary condition for the mathematical model of the air flow in the area under the station platform of Bangkok sky train for Eq. 3 as Fig. 2.

\section{Finite element technique:}

The discretisation of the weak form: Consider the discretisation of the weak form corresponding to Eq. 3 using the finite element method. Let $\omega$ be weighting functions, being arbitrary but $\omega=0$ on $S_{1}$, where the value of $\Phi$ is known. The weighted residual form of Eq. 3 is obtained by:

$$
\iint_{\Omega}\left(\frac{\partial^{2} \Phi}{\partial \mathrm{x}^{2}}+\frac{\partial^{2} \Phi}{\partial \mathrm{y}^{2}}\right) \omega \mathrm{d} \Omega=0
$$

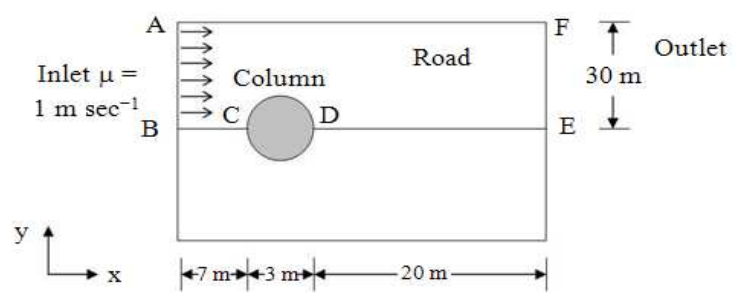

Fig. 1: The area under the station platform of Bangkok sky train with a column (Pochai, 2009)

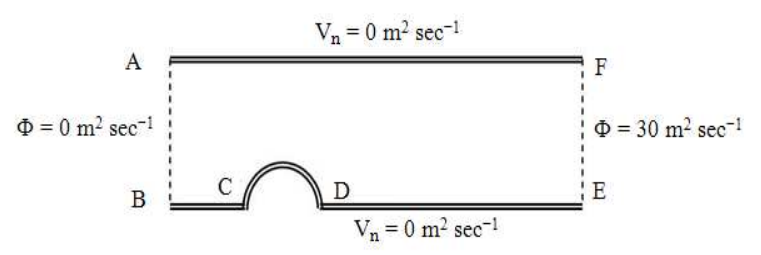

Fig. 2: The revision of boundary condition (Pochai, 2009)

Integration by parts leads to:

$\iint_{\Omega}\left(\frac{\partial \Phi}{\partial \mathrm{x}} \frac{\partial \omega}{\partial \mathrm{x}}+\frac{\partial \Phi}{\partial \mathrm{y}} \frac{\partial \omega}{\partial \mathrm{y}}\right) \mathrm{d} \Omega-\int_{\mathrm{S}_{2}} \frac{\partial \Phi}{\partial \mathrm{n}} \omega \mathrm{d} \Gamma=0$

By substituting the boundary condition of Eq. 5 into Eq. 7 to obtain the weak form:

$\iint_{\Omega}\left(\frac{\partial \Phi}{\partial x} \frac{\partial \omega}{\partial x}+\frac{\partial \Phi}{\partial y} \frac{\partial \omega}{\partial y}\right) d \Omega=\int_{S_{2}} V_{n} \omega d \Gamma$

The domain is subdivided into triangular element. The following interpolation functions are used for the weighting functions:

$$
\begin{aligned}
& \Phi(\mathrm{x}, \mathrm{y})=\sum_{\alpha=1}^{3} \mathrm{~T}_{\alpha}(\mathrm{x}, \mathrm{y}) \Phi_{\alpha}, \\
& \omega(\mathrm{x}, \mathrm{y})=\sum_{\alpha=1}^{3} \mathrm{~T}_{\alpha} \omega_{\alpha},
\end{aligned}
$$

where the shape function $\mathrm{T}_{\mathrm{a}}$ are given by:

$\mathrm{T}_{\alpha}=\frac{1}{2 \Delta^{\mathrm{e}}}\left(\mathrm{a}_{\alpha}+\mathrm{b}_{\alpha} \mathrm{x}+\mathrm{c}_{\alpha} \mathrm{y}\right)$

and:

$$
\begin{aligned}
& \mathrm{a}_{\alpha}=\mathrm{x}_{\beta} \mathrm{y}_{\gamma}-\mathrm{x}_{\gamma} \mathrm{y}_{\beta}, \mathrm{b}_{\alpha}=\mathrm{y}_{\beta}-\mathrm{y}_{\gamma}, \\
& \mathrm{c}_{\alpha}=\mathrm{x}_{\gamma}-\mathrm{x}_{\beta}, \Delta^{\mathrm{e}}=\left(\mathrm{b}_{\alpha} \mathrm{c}_{\beta}-\mathrm{b}_{\beta} \mathrm{c}_{\alpha}\right) / 2,
\end{aligned}
$$


In which $\alpha, \beta, \gamma=1,2,3$. Then the weak form Eq. 8 in each triangular element $\mathrm{e}$ is:

$\sum_{\alpha=1}^{3}\left(\iint_{\mathrm{e}}\left(\frac{\partial \Phi}{\partial \mathrm{x}} \frac{\partial \mathrm{T}_{\alpha}}{\partial \mathrm{x}}+\frac{\partial \Phi}{\partial \mathrm{y}} \frac{\partial \mathrm{T}_{\alpha}}{\partial \mathrm{y}}\right) \mathrm{d} \Omega\right) \omega_{\alpha}=\sum_{\alpha=1}^{3}\left(\int_{\mathrm{s}_{2}^{\mathrm{e}}} \mathrm{V}_{\mathrm{n}} \mathrm{T}_{\alpha} \mathrm{d} \Gamma\right) \omega_{\alpha}$

where, $S_{2}^{e}=S_{2} \cap \partial e$. For each triangular element, we obtain the element equations:

$\sum_{\beta=1}^{3} \mathrm{D}_{\alpha \beta}^{\mathrm{e}} \Phi_{\beta}=\mathrm{F}_{\alpha}^{\mathrm{e}}$ for all $\alpha=1,2,3$,

Where:

$\mathrm{D}_{\alpha \beta}^{\mathrm{e}}=\iint_{\mathrm{e}}\left(\frac{\partial \Phi_{\alpha}}{\partial \mathrm{x}} \frac{\partial \Phi_{\beta}}{\partial \mathrm{x}}+\frac{\partial \Phi_{\alpha}}{\partial \mathrm{y}} \frac{\partial \Phi_{\beta}}{\partial \mathrm{y}}\right) \mathrm{d} \Omega$,

$\mathrm{F}_{\alpha}^{\mathrm{e}}=\int_{\mathrm{S}_{2}^{\mathrm{e}}} \mathrm{V}_{\mathrm{n}} \mathrm{T}_{\alpha} \mathrm{d} \Gamma$

The matrix form of equation: From Eq. 11, it can be obtained the matrix form:

$\left[D^{\mathrm{e}}\right]=\frac{1}{4 \Delta^{\mathrm{e}}}\left[\begin{array}{ccc}\mathrm{b}_{1}^{2}+\mathrm{c}_{1}^{2} & \mathrm{~b}_{1} \mathrm{~b}_{2}+\mathrm{c}_{1} \mathrm{c}_{2} & \mathrm{~b}_{1} \mathrm{~b}_{3}+\mathrm{c}_{1} \mathrm{c}_{3} \\ \mathrm{~b}_{1} \mathrm{~b}_{2}+\mathrm{c}_{1} \mathrm{c}_{2} & \mathrm{~b}_{2}^{2}+\mathrm{c}_{2}^{2} & \mathrm{~b}_{2} \mathrm{~b}_{3}+\mathrm{c}_{2} \mathrm{c}_{3} \\ \mathrm{~b}_{1} \mathrm{~b}_{3}+\mathrm{c}_{1} \mathrm{c}_{3} & \mathrm{~b}_{2} \mathrm{~b}_{3}+\mathrm{c}_{2} \mathrm{c}_{3} & \mathrm{~b}_{3}^{2}+\mathrm{b}_{3}^{2}\end{array}\right]$

and:

$$
\left\{\mathrm{F}^{\mathrm{e}}\right\}=\frac{1}{2} \mathrm{~V}_{\mathrm{n}} \mathrm{1}\left\{\begin{array}{l}
0 \\
1 \\
1
\end{array}\right\}
$$

In our problem, we assumed that $\mathrm{V}_{\mathrm{n}}$ is constant on the boundary segment $\mathrm{S}_{2}^{\mathrm{e}}$, that length is 1 . After assembly of all element equations Eq. 14, it can be obtained:

$[\mathrm{D}]\{\Phi\}=\{\mathrm{F}\}$

The finite element solution: Since the nodal values $\Phi_{\alpha}$ are known and using Eq.(1), the velocity components $u$ and $v$ is obtained by:

$$
\begin{aligned}
& \mathrm{u}=\sum_{\alpha=1}^{3} \frac{\partial \mathrm{T}_{\alpha}}{\partial \mathrm{x}} \Phi_{\alpha}=\frac{1}{2 \Delta^{\mathrm{e}}} \sum_{\alpha=1}^{3} \mathrm{~b}_{\alpha} \Phi_{\alpha} \\
& \mathrm{v}=\sum_{\alpha=1}^{3} \frac{\partial \mathrm{T}_{\alpha}}{\partial \mathrm{y}} \Phi_{\alpha}=\frac{1}{2 \Delta^{\mathrm{e}}} \sum_{\alpha=1}^{3} \mathrm{c}_{\alpha} \Phi_{\alpha}
\end{aligned}
$$

\section{RESULTS}

Numerical experiment: We mesh the domain into 180 triangular elements with 115 nodes as show in Fig. 3 and 4 . From the revision of the boundary, we have the inlet and out let boundaries along $\mathrm{AB}, \mathrm{EF}$ and elsewhere are $\Phi=0, \Phi=30$ and $\mathrm{V}_{\mathrm{n}}=0$, respectively. The calculated results by using the velocity potential are shown in Fig. 5 and Table 1.

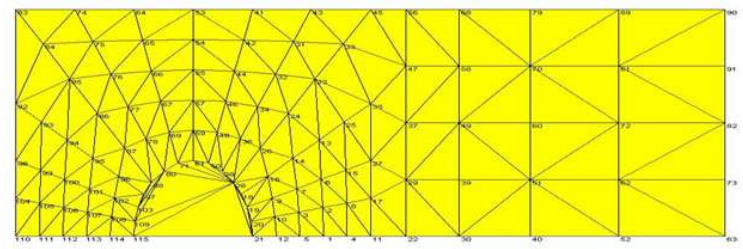

Fig. 3: The domain discretisation

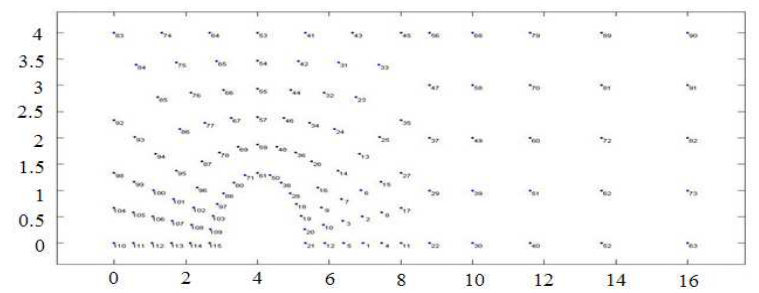

Fig. 4: The nodes numbering

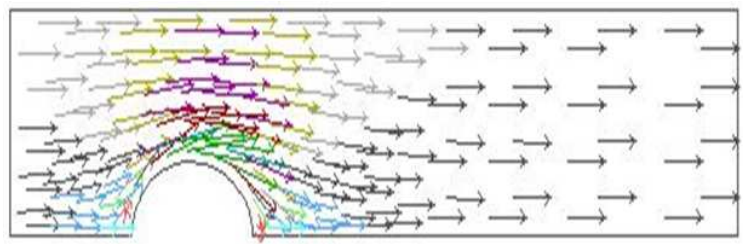

Fig. 5: The flow velocity

Table 1: The calculated flow velocity of some elements of most inside area of the platform

\begin{tabular}{llc}
\hline & $\begin{array}{l}\text { Velocity in } \\
\text { X-direction } \\
\mathrm{u}\left(\mathrm{m} \mathrm{sec}^{-1}\right)\end{array}$ & $\begin{array}{c}\text { Velocity in } \\
\text { Y-direction } \\
\mathrm{v}\left(\mathrm{m} \mathrm{sec}^{-1}\right)\end{array}$ \\
\hline 89 & 0.7256 & -0.1677 \\
81 & 0.6801 & -0.0017 \\
72 & 0.7583 & -0.0009 \\
62 & 0.7357 & 0.0391 \\
52 & 0.6834 & 0.0511 \\
90 & 0.7798 & -0.3263 \\
91 & 0.6286 & 0.0019 \\
82 & 0.7001 & -0.0287 \\
73 & 0.8080 & -0.0014 \\
63 & 0.7576 & 0.0659 \\
\hline
\end{tabular}




\section{DISCUSSION}

The flow velocity of the most inside area of the platform is slower than most outside area. These means that the columns of platform must be a cause of air flow obstacle.

\section{CONCLUSION}

The governing equation with the revised boundary condition for BTS sky train platform is presented. Accordingly, a finite element technique for simulation the air flow and the numerical results are also given. It is obtained that columns of platform is a cause of the air flow obstacle. For the future work, another platform structures could be considered. The field measurement and the numerical result of the air flow in the consideration area should be compared.

\section{ACKNOWLEDGMENT}

This research is financially supported by the KMITL Research Fund, Faculty of Science KMITL Research Fund.

\section{REFERENCES}

Ahmed, A.M., M. Ahmad and A. Rahim, 2010. Effect of size of heated obstruction within room on three dimensional air flow characteristics. Am. J. Eng. Applied Sci., 3: 372-379. DOI: 10.3844/.2010.372.379

Al Jeran, H.O. and A.R. Khan, 2009. The effect of air pollution on ozone layer thickness in troposphere over the state of Kuwait. Am. J. Environ. Sci. 5: 230-237. DOI: 10.3844/.2009.230.237

El-Baz, F., Eltayeb, I.A. and Hassan, M.H.A., 1990. Sand Transport and Desertification in Arid and Semi-arid Lands. World Scientific Publishing Co., Singapore.

Gillette, D. and P. Goodwin, 1974. Microscale transport of sand-sized soil aggregates eroded by wind. J. geophys. Res., 79: 4080-4084. DOI: 10.1029/JC079i027p04080
Hassan, M.H.A. and I.A. Eltayeb, 1991. Timedependent transport of dust. J. Geophys. Res., 96: 9337-9339. DOI: 10.1029/91JD00229

Hassan., M.H.A. and I.A. Eltayeb, 1992. Suspension of transport of wind eroded sand particles, Geophys. J. Int., 104: 147-152. DOI: 10.1111/j.1365246X.1991.tb02500.x

Hassan., M.H.A. and I.A. Eltayeb, 1993. Twodimensional transport of dust from an infinite line source at ground level: non-zero roughness height, Geophys. J. Int., 115: 211-214. DOI: 10.1111/j.1365-246X.1993.tb05599.x

Ninomiya, H. and K. Onishi, 1991. Flow Analysis Using a PC. 1st Edn., Computational Mechanics Publications, CRC Press, Boca Raton, ISBN: 0849377315, pp: 190.

Pasquill, F., 1962. Atmospheric Diffusion. D. Van Nostrand, $\quad$ Princeton. $\quad$ pp: 12. DOI: $10.1002 /$ qj.49708837622

Pochai, N., 2009. A Mathematical Model of the Air Flow in the Area under the Station Platform of Bangkok Sky Train. Proceeding in International Conference on Science, Technology and Innovation for Sustainable Well-Being, July 23rd24th, Faculty of Engineering, Mahasarakham University, Thailand. http://webserv.kmitl.ac.th/konoppar/

Sharan, M., A.K. Yadev, M.P. Singh, P. Agrawal and S. Nigam, 1996. A mathematical model for the dispersion of air pollutants in low wind conditions. Atmos. Environ., 30: 1209-1220. DOI: 10.1016/1352-2310(95)00442-4

Smith, F.B., 1957. The diffusion of smoke from a continuous elevated point source into a turbulence atmosphere. J. Fluid. Mech., 2: 49-49. DOI: 10.1017/S0022112057000737

Takeuchi, M., 1980. Vertical profiles and horizontal increase of drift-snow transport. J. Glaciol., 26: 481-492. http://adsabs.harvard.edu/abs/1980JGlac..26..481T

Townsend, A.A., 1976. The Structure of Turbulence Flow. Cambridge University Press, London. 